\title{
Analyzing bank profile shape of alluvial stable channels using robust optimization and evolutionary ANFIS methods
}

\author{
Azadeh Gholami ${ }^{1,2} \cdot$ Hossein Bonakdari ${ }^{1,2}$ (1) Isa Ebtehaj ${ }^{1,2} \cdot$ Seyed Hamed Ashraf Talesh ${ }^{3}$. \\ Saeed Reza Khodashenas ${ }^{4}$. Ali Jamali ${ }^{3}$
}

Received: 24 July 2018 / Accepted: 7 March 2019 / Published online: 15 March 2019

(c) The Author(s) 2019

\begin{abstract}
In natural rivers and artificial channels in addition to the channel dimensions (widening, reduction in slope and depth in the channel banks), formed shape profile in the case that the sediment on the banks with no movement (thresholds state) is of considerable importance for engineers. To determine the bank shape profiles, various theoretical, empirical and statistical relations have been provided based on physical and numerical models by different researchers. In this study, a simple model of adaptive neuro-fuzzy inference systems (ANFIS) is combined with two algorithms of differential evolution (DE) and singular value decomposition value (SVD) and the performance of these models to predict the stable shape profiles of the channels is evaluated and compared. In this paper, the main goal is to assess extensively the effect of hybrid models based on optimized algorithms (ANFIS-DE) and multi-objective evolutionary algorithm (ANFIS-DE/SVD) in improvement of performance of ANFIS and ANFIS-DE models, respectively. Accordingly, the results assessment show that all three ANFIS, ANFIS-DE and ANFIS-DE/SVD models are perfectly able to predict shape profiles in accordance with the observed profiles for the threshold channels. Using optimized and evolutionary algorithms has a positive impact on the performance of simple model of ANFIS. As compared to the simple ANFIS model, ANFIS-DE approximately $10.1 \%$ and ANFIS-DE/SVD model $7.2 \%$ is improved compared to the ANFIS-DE model. The accuracy of ANFIS-DE/SVD model showed better performance as well about $18.6 \%$ compared to the simple ANFIS model. Therefore, it can be said that not only DE optimization algorithms have a significant impact on increasing the performance of a simple ANFIS model but also using evolutionary algorithms (ANFIS-DE/SVD) reduce the ANFIS-DE model error accordingly. Polynomial equations of bank profiles proposed by hybrid ANFIS models in the present study can be used in design and implementation of cross section of stable channels.
\end{abstract}

Keywords Threshold channel $\cdot$ Bank profile shape $\cdot$ ANFIS $\cdot$ Evolutionary algorithms

\section{Introduction}

The process of channels widening until you reach equilibrium or stable state is continued in the channels, and the final state of this process causes the threshold channel ( $\mathrm{Yu}$

Hossein Bonakdari

Bonakdari@yahoo.com

1 Department of Civil Engineering, Razi University, Kermanshah, Iran

2 Environmental Research Center, Razi University, Kermanshah, Iran

3 Department of Mechanical Engineering, University of Guilan, Rasht, Iran

4 Department of Water Engineering, Ferdowsi University of Mashhad, Mashhad, Iran and Knight 1998). In this case, the bank sediments are on the threshold and the bed particles are moving. This case is a simple model of most natural rivers and channels. Therefore, identification of the type of shape profile created on the banks like as specified channel geometric dimensions of stable channels is important. Concerning to the determination of slope, depth and water surface width in stable state or regime of channels, extensive research has been done (Lee and Julien 2006; Afzalimehr et al. 2010; Métivier et al. 2016; Gholami et al. 2017a; Shaghaghi et al. 2017; Joshi et al. 2018). But there is little research to determine the type of bank profiles. The first study in this regard is the approach of Glover and Florey (1951), which is an adaptation of tractive force approach related to US Bureau of Reclamation (USBR). Lateral diffusion term caused by the turbulence in his equations is ignored and cosine curve proposed for the 
banks. Parker (1978) justified the non-uniform shear stress distribution on the banks and channel bed by considering the lift force on the channel banks. In this case, initial cosine curve profile is modified. Ikeda et al. (1988) considered the main factor in holding stable state of the channels as lateral momentum transfer channels caused by turbulence that is lead to a reduction in the shear stress distribution from bed to the banks. The exponential shape is proposed for the channel banks in this case. Pizzuto (1990) stated that the channel widening and erosion in the channel banks are continued until to attain an equilibrium state. The exponential function was introduced in this case, but in following by flatting the channel bed the profiles shape of banks will be cosine curve. Diplas and Vigilar (1992) proposed the fifth-degree polynomial with a numerical solution of diffusion equations for fluid flow and balance forces equation for bank particles. Vigilar and Diplas (1997) by providing a numerical model considered the transition of momentum caused by the turbulence as a function of the flat bed width of the channel. They presented the three-degree polynomial function for shape profile of stable channel. Cao and Knight (1997) explained the non-moving particles in the banks by using the combination of the entropy concept with continuity equations and sediment transport relationships and proposed the parabolic curve for the bank profiles. Babaeyan-Koopaei and Valentine (1998) were one of the researchers that carried out several experimental studies on measuring the stable channel shape and dimensions. A hyperbolic function was fitted on their experimental results. For other experimental studies it can be noted to Stebbings (1963), Mikhailova et al. (1980), Ikeda (1981) and Diplas (1990) studies. Dey (2001) by providing a simple numerical code considered the momentum transformation as a function of transverse distance from the channel center which is described by a power law. Khodashenas (2016) examined extensive experimental research on the threshold channel at different flow discharges. By comparing the results with predecessor's model, results stated that the most conformity was seen with the Vigilar and Diplas (1998) results and the best shape for the banks is introduced as polynomial. Most mentioned studies are based on laboratory methods and numerical codes which are very timeconsuming and costly. Gholami et al. (2018b) for the first time investigated the ability of artificial intelligence (AI) method in prediction of banks shape profile of threshold channels based on different observed datasets using robust gene expression programming (GEP) model. They presented a reliable relationship in estimating vertical boundary levels of channel banks with acceptable accordance with observed values.

Today, the application and development of the artificial intelligence (AI) method have been common in many sciences (Gholami et al. 2016a, b, 2019; Diop et al. 2018; Ebtehaj et al. 2016, 2018, 2019; Singh et al. 2017; Ghorbani et al. 2018; Li et al. 2018; Sanikhani et al. 2018; Sulaiman et al. 2018; Tao et al. 2018a, b; Yaseen et al. 2018a). Among these methods, fuzzy models of Takagi-Sugeno-Kang (TSK) as an adaptive neuro-fuzzy inference system (ANFIS) are known (Manu and Thalla 2017). To increase the speed and performance of ANFIS models, using optimization algorithms (Hosseini et al. 2016; Gholami et al. 2017b; Bonakdari and Zaji 2018; Karaboga and Kaya 2018) and evolutionary models (multi-objective optimization) (Dariane and Azimi 2016; Ahmadianfar et al. 2017; Saba et al. 2017; Karkevandi-Talkhooncheh et al. 2017; Nouiri 2017) has been very common. Regarding the use of AI methods in prediction of the stable channel geometry dimensions (width, depth and slope), it can be noted to Madvar et al. (2011), Taher-Shamsi et al. (2013), Bonakdari and Gholami (2016), Gholami et al. (2017a), Shaghaghi et al. (2017, 2018a, b). All of them referred to high ability of AI models in prediction of stable channels geometry. However, regarding application of AI methods (especially different ANFIS models) in estimation of cross-sectional banks shape profile of stable channels, it can be pointed out to recent contributions of authors. Accordingly, Gholami et al. (2018c) assessed the ability of evolutionary algorithm of particle swarm optimization (PSO) algorithm and genetic algorithm (GA) combined with ANFIS model. Their results showed the ANFIS-PSO/GA has an acceptable agreement with observed data with the relative error index of 0.1557 in prediction of vertical boundary level of stable channel shape profile. Gholami et al. (2018a) evaluated the ability of ANFIS-DE/SVD in prediction of the vertical boundary level of the stable channel. They referred to the high accuracy of this type of evolutionary algorithms combined with ANFIS model. DE algorithm has ability to choose the optimal nonlinear coefficient of Gaussian membership function. On the other hands, the SVD can calculate the ANFIS consequent part's linear coefficients. Therefore, the examination of these algorithms in detail compared to each other in combination with ANFIS model is of great importance and necessary to choose them as alternatives to classic ANFIS model.

Therefore, the aim of this study is to evaluate the performance of classic ANFIS model, ANFIS optimized using differential evolution (DE) (ANFIS-DE) and ANFIS optimized multi-objective evolutionary algorithm using SVD (ANFIS-DE/SVD) compared to each other in estimation of banks shape profile of stable channels. Indeed, based on the previous literature studies that we conducted, the main goal of the present paper is evaluating the impact of hybridization in classic ANFIS method, extensively to choose the optimal and efficient method in measuring cross-sectional shape of stable channels. In this study, the question of "whether improvements of ANFIS models using different optimization and evolutionary methods in better prediction of the shape profiles of stable channel banks are effective or not?" 
is answered. At first, the experimental studies of the coordinates of the points located on the boundary of the stable channel at four different discharges in the laboratory are measured by the authors. Then, using these data the models of ANFIS, ANFIS-DE and ANFIS-DE/SVD are trained and tested. The performance of these models in prediction of bank shape profiles is evaluated and compared with each other (ANFIS-DE compared to ANFIS and ANFIS-DE/SVD compared to ANFIS-DE), and also the best model is presented. Furthermore, the capability of these hybrid models is assessed in different flow discharge values and the proposed shape profile is presented accordingly.

\section{Experimental work}

In this study, four laboratory sets by the authors in hydraulic laboratory of the Department of Civil and Geological of the University of Saskatchewan, Canada, to measure the two parameters of depth or vertical level of points $(y)$ located on the channel boundary and the transverse distance of the points from the channel axis $(x)$ are done in an equilibrium channel state. The used flume of the channels has dimensions of $20 \times 1.22 \times 0.6 \mathrm{~m}$ in length $\times$ width $\times$ height directions. The channel bottom is filled of uniform sand with $d_{50}=0.053 \mathrm{~mm}$. Cross-sectional shape is in two triangular and trapezoidal modes. Experiments are done in four different discharges of 1.157, 2.18, 2.57 and 6.2 1/s. Laboratory sets specification is shown in Table 1 . A magnetic flow meter is used to measure the flow discharges. Deal of conducting the experiments is like that in each runs the desired discharge passed through the channel and to achieve the equilibrium state in the channel cross section and plan the discharge is kept constant. The passed through water is drained from the channel and channel geometry and coordinate points specifications in the stable channel boundary are measured at different cross sections. Two levels of channel water and bed using a point gages at different transverse distances of 8,9 , and $11 \mathrm{~m}$ from the channel entrance are measured. Also point gauge measurements by a laser gauge are checked. In this experiment, the flow parameters at stable state in two different cross sections: channel upstream end

Table 1 Different experiment characteristics

\begin{tabular}{llllll}
\hline Test no. & $\begin{array}{l}\text { Dis- } \\
\text { charge } \\
(Q)(1 / \mathrm{s})\end{array}$ & $d_{50}(\mathrm{~mm})$ & $S$ & $h(\mathrm{~cm})$ & $\begin{array}{l}\text { Cross section's } \\
\text { shape }\end{array}$ \\
\hline 1 & 1.157 & 0.53 & 0.0023 & 37 & Triangular \\
2 & 2.57 & 0.53 & 0.0023 & 61.3 & Triangular \\
3 & 6.2 & 0.53 & 0.0023 & 80 & Triangular \\
4 & 2.18 & 0.53 & 0.0023 & 61.2 & Compound channel \\
\hline
\end{tabular}

points with zero bed load, and the downstream channel end points with a maximum bed load on the channel bed (wider cross section) which is measured. In this study, the results of measured dimensions and shape of the stable channel related to the first mode (upstream end points) are used. A view of a laboratory flume is shown in Fig. 1. The channel shape in stable state is a particular importance in the formation of banks profile geometric forms. Figure 2 shows two bank profiles characteristic. In this figure, $x$ and $y$ are the transverse and vertical distance from the central axis of the channel bed (m), $h$ is the flow depth in the channel centerline, and $T$ shows the water surface width, respectively. The bank profile characteristics are dimensionless as follows:

$y^{*}=y / h$ and $x^{*}=x / h, T^{*}=T / h$.

where $x^{*}, y^{*}$ and $T^{*}$ are dimensionless values of $x, y$, and $T$.

\section{Evolutionary Pareto design of ANFIS}

Gholami et al. (2018a) applied DE and SVD model in hybrid with ANFIS model. They expressed the rules of these methods extensively and detailed. In this section, how to optimize the ANFIS networks to model the thresholds channel bank profile by combining this method with differential evolution (DE) as an evolutionary algorithm and singular value decomposition (SVD) as a powerful numerical method is expressed in summary.

\section{Modeling using ANFIS}

ANFIS network includes a set of IF-THEN fuzzy rules of fuzzy systems of TSK (Takagi and Sugeno 1985). This network is capable of modeling to establish a mapping between inputs of multi-inputs with one output (multi-inputs-single outputs) as well. In an identification problem, the main goal is to find the function $\hat{f}$ as using leads to a good accuracy estimation of actual $\mathrm{f}$ function. In fact, this function using an input vector $X=\left\{x_{1}, x_{2}, \ldots, x_{n}\right\}$ estimates the function $\hat{f}$ as obtained $y$ as closely as possible to be close to

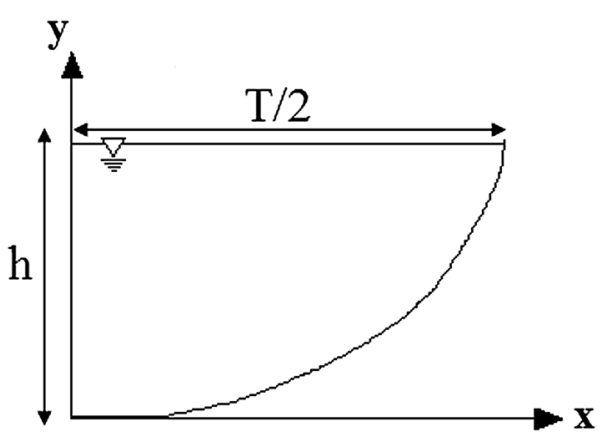

Fig. 1 Geometry definition sketch of bank profile in stable channel 



Fig. 2 A view of studied laboratory flume

the actual value using mean square error (MSE) (Gholami et al. 2018a). TSK fuzzy rules of the ANFIS models can be expressed as follows:

$$
\begin{gathered}
\text { Rule }_{l}: \text { IF } x_{1} \text { is } A_{l}^{\left(j_{1}\right)} \text { AND } x_{2} \text { is } A_{l}^{\left(j_{2}\right)} \text { AND } \ldots x_{n} \text { is } A_{l}^{\left(j_{n}\right)} \\
\text { THEN } y=\sum_{i=1}^{n} w_{i}^{l} x_{i}+w_{0}^{l}
\end{gathered}
$$

where $j_{i} \in\{1,2, \ldots, r\}$ and $W^{l}=\left\{w_{1}^{l}, w_{2}^{l}, \ldots, w_{n}^{l}, w_{0}^{l}\right\}$ are parameter sets related to the consequent part of each TSKtype fuzzy rules. The fuzzy sets due to the good performance Gaussian membership function (Azimi et al. 2016; Khoshbin et al. 2016) are considered as a Gaussian shape in the range of $\left[-\alpha_{i},+\beta_{i}\right] \quad(i=1,2, \ldots, n)$ (Gholami et al. 2018a). Each fuzzy set $A^{(j)}(j=\{1,2, \ldots, r\})$ which has a Gaussian shape is defined as follows:

$\mu_{A^{(j)}}\left(x_{i}\right)=\exp \left(\left(-\frac{x_{i}-c_{j}}{2 \sigma_{j}}\right)^{2}\right)$

where $\sigma_{j}$ and $c_{j}$ are variances and centers (respectively) related to parameters antecedent part. These parameters should be adjusted to gain the optimized results. It is clear that the number of parameters in the antecedent part of ANFIS is equal to the multiplication of the input vector $(n)$ in the number of fuzzy sets in each antecedent ( $n r)$ (Gholami et al. 2018a). By Mamdani algebraic product concept, the degree of TSK-type fuzzy IF-THEN rules could be assessed (Gholami et al. 2018a).

The $\mu_{A_{l}\left(j_{i}\right)}\left(x_{i}\right)$ is the membership function degree of $\mathrm{x}_{\mathrm{i}}$ concerning their linguistic value of $l$ th fuzzy rules $\left(A_{l}^{\left(j_{i}\right)}\right)$. A singleton fuzzifier regarding product inference engine and accumulation of individual contribution of each fuzzy rules results in following fuzzy system form:

$f(X)=\frac{\sum_{l=1}^{N} y_{l}\left(\prod_{i=1}^{n} \mu_{A_{l}^{\left(j_{i}\right)}}\left(x_{i}\right)\right)}{\sum_{l=1}^{N}\left(\prod_{i=1}^{n} \mu_{A_{l}^{\left(j_{i}\right)}}\left(x_{i}\right)\right)}$

The above relationship is a set including the number $N$ of fuzzy rules as Eq. (1). The above equation can be rewritten in linear form as follows: 


$$
f(X)=\sum_{l=1}^{N} p_{l}(X) y_{l}+D
$$

where $D$ is the difference of predicted value $(f(X))$ and corresponding real value $(y)$. It is evident that for a set of pair data of multi-inputs-single output $\left(x_{i}, y_{i}\right)(i=1,2, \ldots, m)$, Eq. (4) is rewritten as matrix form:

$Y=P W+D$

where $W=\left[w_{1}, w_{2}, \ldots, w_{s}\right]^{\mathrm{T}} \in R^{s}, \quad S=N(n+1)$, and $P=\left[p_{1}, p_{2}, \ldots, p_{s}\right]^{\mathrm{T}} \in R^{m \times S}$.

Since the number of data pairs used in the model training process is usually more than all the coefficients in the conclusion part of TSK-type fuzzy rules, the rules are sufficiently small. These conditions lead to a leastsquare approximation process to estimate the unknowns $W=\left[w_{1}, w_{2}, \ldots, w_{s}\right]^{\mathrm{T}}$, as the difference between the actual and predicted values $(D)$ is minimized (Gholami et al. 2018a). Correction of coefficients in the conclusion part of fuzzy rules similar to those described above leads to better estimation of data pairs for multiinputs-single output $\left(x_{i}, y_{i}\right)(i=1,2, \ldots, m)$ which reduce the vector $D$ as much as possible that shows the difference between estimated and actual values. Using direct methods to solve main normal equations shows too much sensitivity to round-off and, more importantly, is prone singularity. Therefore, to avoid this, in this study, singular value decomposition (SVD) as a powerful and widely used numerical method to calculate the linear coefficients corresponding to the conclusion part of TSK-type fuzzy rules to avoid the risk of singularity in Eq. (5) is used. In addition, in this study using a combination of SVD and differential evolution (DE), ANFIS network optimization design for modeling of thresholds channel bank profile is done. Details about the combination of SVD and DE methods are expressed in following.

\section{Application of DE in optimize design of ANFIS}

In this study, to have an optimal design parameters membership function of the network ANFIS algorithm DE (Storn and price 1997) is used. The used membership function in this study is in the Gaussian form (Eq. 2) (Gholami et al. 2018a). Coefficients set that should be optimized in this function to model the thresholds channel bank profile with the least amount of errors are as $\{c, \sigma\}$. An overview of the algorithm DE and operators in this algorithm was expressed in Gholami et al. (2018a).

\section{Overview of DE}

Differential evolution (DE) which is introduced by Storn and price (1997) is a population-based evolutionary algorithm for universal optimization of continuous search domain. Accordingly, using mechanisms defined for algorithm that includes operators crossover (or recombination), selection and mutation proceeds in development and optimization of random respond vector is considered (Gholami et al. 2018a). In following, the basic control variables related to the algorithms include population size (NP) crossover constant (CR) and mutation scale factor $(F)$ which expressed distinctly.

Mutation DE algorithm by adding differences between vectors of two populations to a third vector, the new vectors parameter is generated. This function is known as mutation. Then, to obtain a trial vector, mutated vector parameters with an estimated vector (target vector) are combined; for each target vector, a mutant vector is defined as follows:

$v_{i, G+1}=x_{r 1, G}+F *\left(x_{r 2, G}-x_{r 3, G}\right)$

$x_{i, G}=1,2, \ldots, \mathrm{NP}(\mathrm{NP}$ is population size which is constant during search process).

In the above equation, coefficients $r_{1}, r_{2}, r_{3}$ are defined members of the population for the problem which are selected randomly as any one of them is similar to each other. In the above equation, the parameter $F$ is scaling factor. This factor controls the differential variation related to $\left(x_{r 2, G}-x_{r 3, G}\right)$. DE mutation operator is presented in Fig. 3 .

Crossover In this function, parent and mutant vectors are combined and trial vector $\left(u_{j i}, G+1\right)$ which are defined as follows is created:

$u_{j i, G+1}= \begin{cases}u_{j i, G+1} & \text { if }\left(\mathrm{rnd}_{j} \leq \mathrm{CR}\right) \text { or } j=r n_{i}(j=1,2,3, \ldots, D) \\ x_{j i, G+1} \text { if }\left(\mathrm{rnd}_{j}>\mathrm{CR}\right) \text { and } j \neq r n_{i}(j=1,2,3, \ldots, D)\end{cases}$

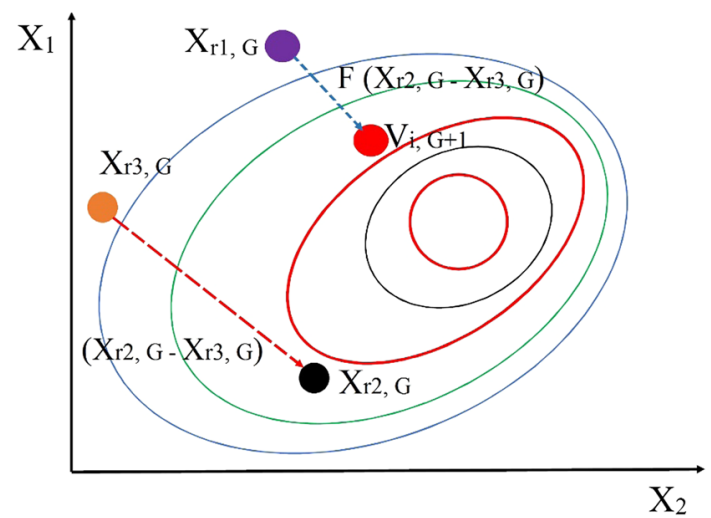

Fig. 3 Mutation operation in DE

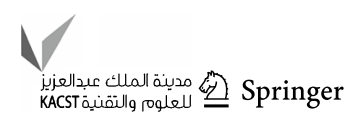


where $\mathrm{CR} \in[0,1]$ is the crossover constant, $\operatorname{rnd}_{j} \in[0,1]$ is a random value, $D$ is dimensions of a vector, and $\mathrm{rn}_{i} \in(1,2,3, \ldots, D)$ is the randomly chosen index.

Selection This operator evaluates the trial vector generated by the crossover and mutation operators. In fact, the performance of target and trial vector is compared and vectored with better performance is selected. If the target function value of the vector trial is less, the vector in the target vector is copied and used in the next generation. Otherwise, target vector is transferred to the next generation.

$x_{i, G+1}= \begin{cases}u_{i, G+1} & \text { if } f\left(u_{i, G+1}\right) \leq f\left(x_{i, G}\right) \\ x_{i, G+1} & \text { Otherwise }\end{cases}$

\section{Mutation scale factor distribution control}

To achieve an optimal design of the system ANFIS, it is needed to determine the amount of DE algorithm operators. NP and $F$ values should be determined. NP value using trial and is considered 80 , but the mutation scale factor $(F)$ using trial and error is difficult. In this study, the amount of the operator using the distance $F$ from the optimal solution is obtained. As parents vector positions in large amounts, so that of Pareto front indicates its great distance from the optimum population. Thus, according to far distance from optimal solution, more search solution to achieve optimized solution of mutation scale factor $(F)$ is required and its value is closer to 1 . Due to the near condition to optimal solution and limited space search, Pareto front in the lower layer decreases toward zero. Diagram, Pareto front schematic figure to determine the mutation scale factor $(F)$ is as Fig. 4 (Gholami et al. 2018a).

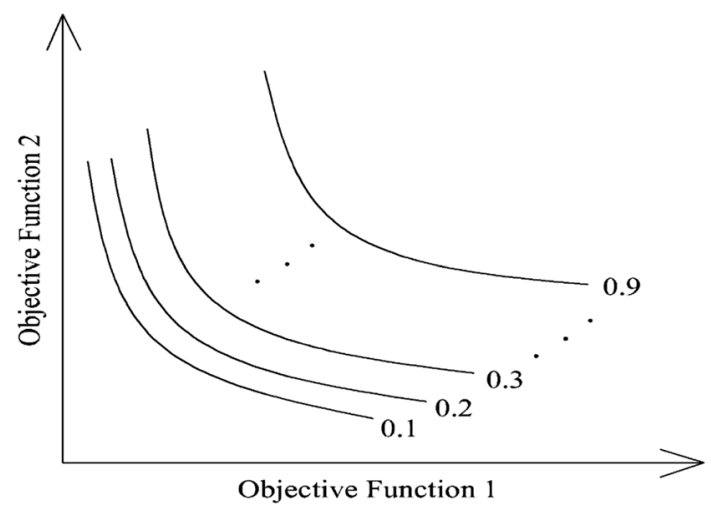

Fig. 4 Mutation scale factor $(F)$ based on proximity to optimal solution in Pareto front (Azimi et al. 2016)

\section{Application of SVD in ANFIS design}

In this study, the optimum design and estimation of linear parameters of the conclusion part of fuzzy sets, the SVD (Golub and Reinsch 1970) is used. This method to solve the least-square problem that singularity is there in the governing equations is used (Azimi et al. 2016). SVD of the matrix $P \in R^{M \times S}$ is consist of the factorization of it and produces three different matrices including a diagonal matrix that has nonnegative components to prevent of singular values $Q \in R^{S \times S}$, a column-orthogonal matrix $U \in R^{M \times S}$ and orthogonal matrix $V \in R^{S \times S}$ is (refer to Gholami et al. 2018a for more explanations).

\section{Bank profile of threshold channel modeling by ANFIS-DE/SVD}

In this study, to model and optimal estimation of the bank profile of threshold channel using the method presented in this study (ANFIS-DE/SVD), the Pareto curve is used. By defining functions training error (TE) and predicting error (PE) as objective functions, the optimal point regarding the model performance in both mentioned target function is evaluated and optimal point selected. To select an optimal point, nearest to ideal point (NIP) (Khalkhali et al. 2016) method is used. The TE, PE, and Trd points presented in Fig. 5 represent the point with the largest prediction error, the point with the most training error showing the optimal point (respectively). In fact, the main goal is to find the point Trd that simultaneously in both training and prediction model mode show good performance which is selected as the optimal point. Also, Fig. 6 shows the graph of Gaussian membership function (MF), for each inputs of the present

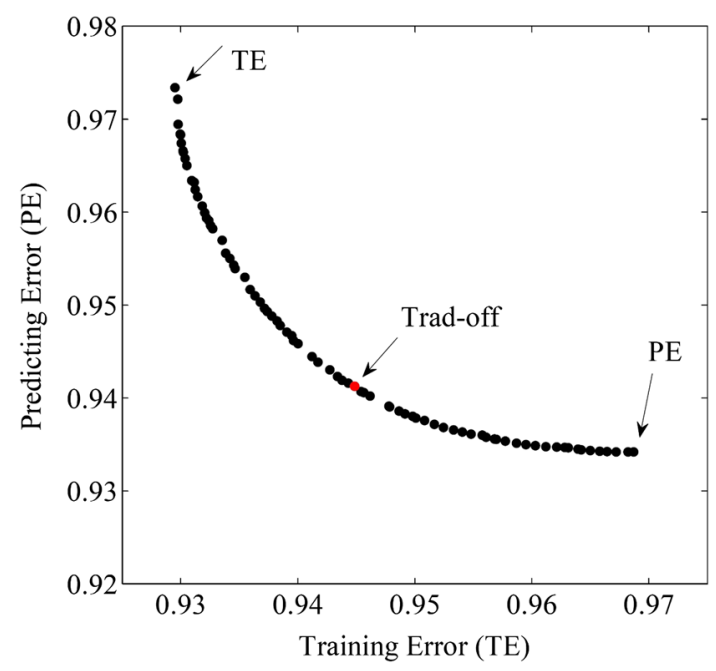

Fig. 5 Pareto curve of training error and prediction error 
Fig. 6 Optimal membership function form of the trade-off design point
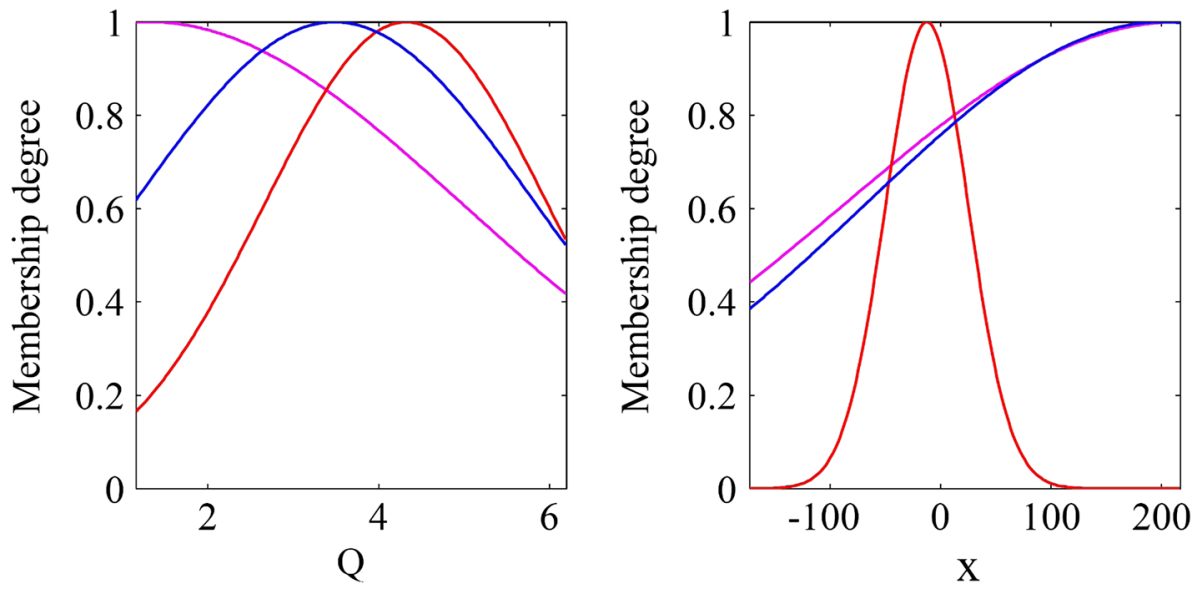

Table 2 Optimal parameters of Gaussian membership functions in trade-off point

\begin{tabular}{llr}
\hline & $Q$ & \multicolumn{1}{l}{$X$} \\
\hline$\sigma$ & 3.69 & 303.04 \\
& 1.67 & 37.42 \\
& 2.37 & 270.76 \\
$C$ & 1.32 & 214.92 \\
& 4.32 & -12.21 \\
& 3.48 & 201.70 \\
\hline
\end{tabular}

problem $(Q, x)$. The values of these functions using a combination of DE and SVD method with ANFIS for the optimal point are obtained. Optimal values for each input are presented in Table 2. Axes $x$ and $y$ in the figure represent the amount of input parameters ( $Q$ or $x$ ) and the respective membership degree. Also according to the figure, it is observed that the number of membership functions in this study, for each input is equal to 3 .

\section{Statistical error criteria for models performance}

In the present study to assess and evaluate the performance of ANFIS, ANFIS-DE and ANFIS-DE/SVD models, various statistical indices are used. Three indices of absolute error mean error (ME), mean absolute error (MAE) and root-mean-squared error (RMSE) and relative error mean absolute percentage error (MARE) and other statistical parameters BIAS and $\rho$ according to Eqs. (9-16) are used (Khosravi et al. 2018; Yaseen et al. 2018b).

$\mathrm{ME}=\frac{1}{n} \sum_{i=1}^{n}\left(y_{i}-\hat{y}_{i}\right)$

$\mathrm{MAE}=\frac{1}{n} \sum_{i=1}^{n}\left|y_{i}-\hat{y}_{i}\right|$

$$
\begin{aligned}
& \text { RMSE }=\sqrt{\frac{1}{n} \sum_{i=1}^{n}\left(y_{i}-\hat{y}_{i}\right)^{2}} \\
& \text { MARE }=\frac{1}{n} \sum_{i=1}^{n}\left(\frac{\left|y_{i}-\hat{y}_{i}\right|}{y_{i}}\right)
\end{aligned}
$$

$R=\frac{\sum_{i=1}^{n}\left(y_{i}-\bar{y}_{i}\right) \cdot\left(\bar{y}_{i}-\overline{\hat{y}}_{i}\right)}{\sqrt{\sum_{i=1}^{n}\left(y_{i}-\bar{y}_{i}\right)^{2} \sum_{i=1}^{N}\left(\hat{y}_{i}-\overline{\hat{y}}_{i}\right)^{2}}}$

$\mathrm{BIAS}=\frac{\sum_{i=1}^{n}\left(\hat{y}_{i}-y_{i}\right)}{n}$

$\mathrm{SI}=\frac{\mathrm{RMSE}}{\frac{1}{n} \sum_{i=1}^{n} y_{i}}$

$\rho=\frac{\mathrm{SI}}{1+R}$

In the above equations, $y_{i}, \bar{y}_{i}$ and predicted values and $\bar{y}_{i}, \overline{\hat{y}}_{i}$ average of these values are observed, respectively, and $n$ is the number of parameters. Error indices MAE, RMSE, MAE and MARE represent the difference between the model and the observed values with the same unit and scale. The value close to zero of these indices presents a more accurate and less difference between the models with observed data (Kisi and Yaseen 2019). BIAS index shows the performance models in estimation of the values as negative and positive values indicate underestimation and overestimation of the model. SI index values are dimensionless index of RMSE. Error functions showed only the error between observed data and the model error values and there is no correlation 
between them. Therefore, using an index that simultaneously shows the error value and the correlation between the values appears appropriate index. Hence, this study investigates the index $\rho$ as an ideal index to compare the models (Gandomi and Roke 2013; Gholami et al. 2017c, d).

\section{Results and discussion}

Figure 7 shows the regression plots for the predicted $y^{*}$ values by ANFIS, ANFIS-DE and ANFIS-DE/SVD models compared to the corresponding observed values in two train and test mode. In addition, various error index values for each model are estimated and also bar graph to compare the models is drawn in this figure. It can be seen from



Fig. 7 Scatter plots of the $y^{*}$ value predicted by the ANFIS, ANFIS-DE and ANFIS-DE/SVD models compared to the corresponding laboratory values and error index bar graphs 
the graphs that in ANFIS model data are far from the exact line and the fitted line with a large gap is located on the right side. Also, it can be seen in the bar graph that the MARE index value in the ANFIS model is higher than the rest ANFIS-DE and ANFIS-DE/SVD models which using two DE and DE/SVD algorithms, the simple ANFIS model accuracy is increased (respectively, about $8.6 \%$ and $14 \%$ in the train mode). According to $R^{2}$ values close to 1 , in all three models it can be realized that models are capable of predicting the coordinates of points on the stable channel boundaries. $\rho$ index that combines the two indices $R$ and SI is able to express the correlation between the data with error between them (Gandomi and Roke 2013). It is clear from the values of this index that value of this index in the ANFIS-DE/SVD model is less than the other two models that represent the less error of this model in prediction. In this model, the impartial value close to zero of index ME $(-7.8 \mathrm{E}-8)$ (which represents the actual difference between the predicted and observed data) than the other two models has also considerable differences. Moreover, in comparison with ANFIS-DE compared to ANFIS, it can be seen that almost all error indexes in ANFIS-DE are more less than these indexes in ANFIS model which represents the more efficiency of ANFIS-DE. Also, the high performance of ANFIS-DE/SVD compared to ANFIS-DE model is confirmed according to error indexes values. Therefore, it can be pointed out to high effect of optimized (ANFIS-DE) and evolutionary algorithms (ANFIS-DE/SVD) to improve the performance of ANFIS and ANFIS-DE models, respectively.

The positive and negative values of BIAS index indicate the model underestimation and overestimation, respectively, which can be seen from the positive values of this index in ANFIS model confirming the model overestimation. Overestimation of ANFIS model can be seen in large amounts of predicted $y^{*}$ value and can be said that this model predicts the coordinate in the points near the water surface much greater than the observed data. The comparison of the water surface profiles predicted by the three models and the impact of flow discharge parameter $(Q)$ is discussed in the subsequent sections. SI is the dimensionless index of RMSE (squared difference between predicted and experimental) that lacks accuracy of this model in large $y^{*}$ leading to an increase in this index (and larger bar length in the bar graph) in ANFIS model to the two other. Using DE optimization algorithm improves the ANFIS model performance, and the use of evolutionary algorithms DE/SVD also has a considerable impact on the performance of the model ANFIS-DE. It can be said in this paper that ANFIS-DE/SVD model with the lowest values of relative error (0.0940) than the ANFIS (0.1165) and ANFIS-DE (0.1072) is selected as the superior model. Therefore, it can be said that the proposed ANFISDE and ANFIS-DE/SVD can be used as alternative to classic ANFIS model in accurate estimation of stable channels shape and dimensions. These models can accurately detect the erosion and sedimentation processes of profiles formed on channel banks after reaching stable state or threshold motion of sediments in banks. Furthermore, it seems that the proposed hybrid methods can detect the widening free water surface during stability state due to overestimation of classic ANFIS model in these areas. So, using these hybrid models it can be confidently assured in implementation and execution of stable channels in urban watersheds.

In Fig. 8, stable bank profiles predicted by the three ANFIS model with experimental model with different itemizations of results have been compared at different discharges. Also, the bar graphs of error index for these three models are plotted in Fig. 9 in two different modes as the model performance at each four different discharges and the error resulted from the model is shown at each discharge. It can be seen from Fig. 9 that by increasing flow discharge almost in all three models, the less error index values are seen; especially in the model ANFIS-DE/SVD, the MARE value equal to 0.188 in discharge of $1.157 \mathrm{l} / \mathrm{s}$ reaches to 0.088 in discharge of $6.2 \mathrm{l} / \mathrm{s}$ (reduction about 53\%). The highest and lowest amount of errors in all three models is in the minimum and maximum flow discharge, respectively $(1.157 \mathrm{l} / \mathrm{s}$ and $6.2 \mathrm{l} / \mathrm{s}$ ). A notable point in the graphs is that ANFIS-DE and ANFIS-DE/SVD models at high discharge rates have the lowest error which can be mentioned as an advantage of the hybrid models presented in this research. Therefore, the proposed hybrid models can well predict and detect the complicated flow pattern in high discharge values in field open channel compared to classic ANFIS model. These hybrid models are able to detect the widening free water surface, gradually increasing flow depth and decreasing transverse slope of banks with high adaption with observed values. These processes are occurred by channel to adjust its pattern in plan and cross-sectional shapes during to reach stable state in alluvial natural channels (Yalin 1992; Ackert 2000). In Table 3, the error index value for the models at different discharges and also for the entire discharges (average) has been estimated in test mode. It can be seen from the table data that although at two discharges of 1.157 and $2.57 \mathrm{l} / \mathrm{s}$, respectively, ANFIS-DE and ANFIS models have the lowest error indices, but in both discharges of 2.18 and $6.2 \mathrm{l} / \mathrm{s}$, the error index in the ANFIS-DE/SVD model is the lowest amount. So that, it can be seen that the ANFIS-DE/SVD model can accurately estimate the widening in water surface almost similar to observed values better than classic ANFIS model which is physical justification of proposed hybrid models in this paper as before mentioned. Thus, using two-objective evolutionary algorithm of SVD significantly increases the efficiency and accuracy of ANFIS-DE and also ANFIS models. Also, both hybrid models of ANFISDE and ANFIS-DE/SVD are capable of predicting the flow pattern in stable channels after stability with hig adaption

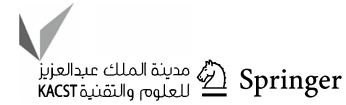


Fig. 8 Stable channel bank profiles predicted by the three models of ANFIS, ANFIS-DE and ANFIS-DE/SVD in comparison with laboratory values at different discharges and their fitted curves
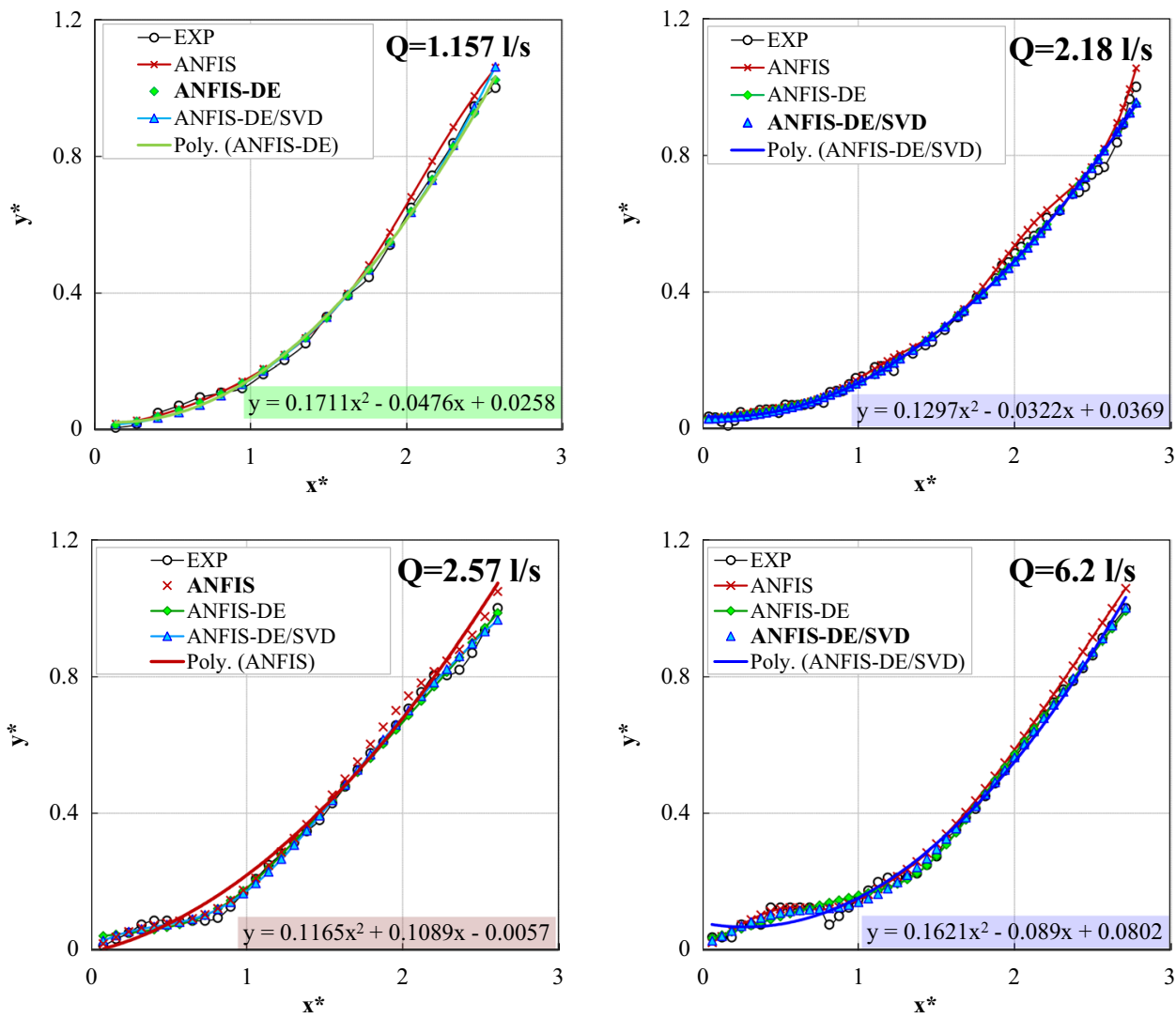

(a)

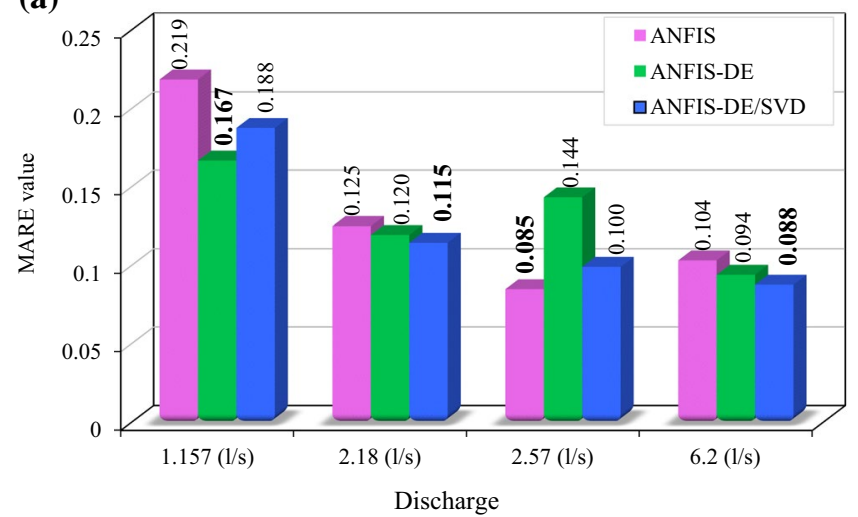

(b)

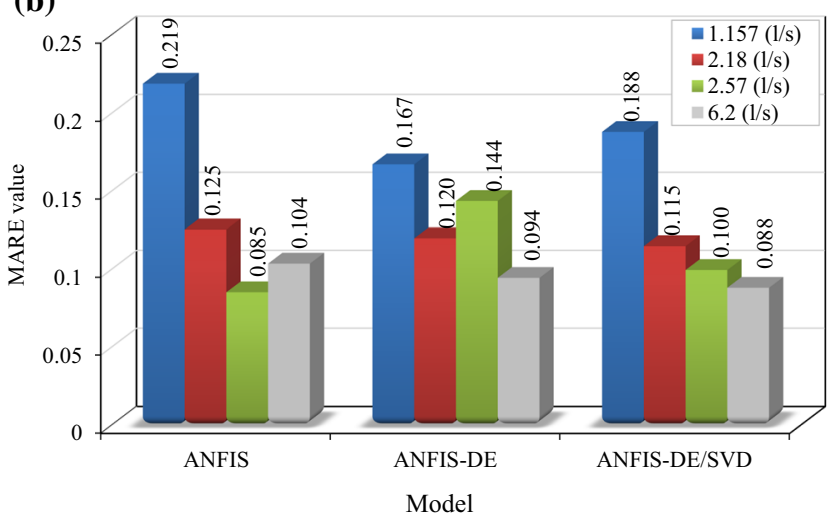

Fig. 9 Bar graphs error index MARE $\mathbf{a}$ at each discharge for three ANFIS, ANFIS-DE and ANFIS-DE/SVD models and $\mathbf{b}$ evaluation of the model performance at each model at four different discharge

with observed values. On the other hands, also in the lowest discharge $(1.157 \mathrm{l} / \mathrm{s})$, the ANFIS-DE model compliance with experimental data was evident that is more accurate than ANFIS model; therefore, using optimization algorithms of DE has a significant role in improvement of performance of ANFIS model. ANFIS-DE/SVD model difference with experimental data at discharge of $1.157 \mathrm{l} / \mathrm{s}$ in the level close to water surface is clear that by increasing the flow discharge the model accuracy is increased and at discharge of $6.21 / \mathrm{s}$ is perfectly compliance with experimental values. By increasing the flow discharge to $2.57 \mathrm{l} / \mathrm{s}$, although ANFIS model error is less than the other two, but the compliance of values predicted by the ANFIS-DE and ANFIS-DE/SVD models at the levels close to water surface with experimental values is more. It can be said that ANFIS-DE and ANFIS-DE/SVD models are well able to predict the water surface widening by increasing discharge through the channel as mentioned before. Cross-sectional shape over time is important in stable 
Table 3 Evaluation and comparison of the model ANFIS, ANFISDE and ANFIS-DE/SVD at different discharges and in total (average) using various statistical indices (test mode)

\begin{tabular}{|c|c|c|c|c|c|}
\hline $\begin{array}{l}\text { Discharge } \\
(1 / \mathrm{s})\end{array}$ & Models & MARE & RMSE & MAE & $\mathrm{ME}$ \\
\hline \multirow[t]{3}{*}{1.157} & ANFIS & 0.220 & 0.0007 & 0.0215 & -0.018 \\
\hline & ANFIS-DE & 0.167 & 0.00017 & 0.0120 & -0.0012 \\
\hline & $\begin{array}{l}\text { ANFIS-DE/ } \\
\text { SVD }\end{array}$ & 0.188 & 0.00035 & 0.0140 & -0.003 \\
\hline \multirow[t]{3}{*}{2.18} & ANFIS & 0.125 & $8.5 \mathrm{E}-5$ & 0.0049 & -0.0035 \\
\hline & ANFIS-DE & 0.1198 & $7.1 \mathrm{E}-5$ & 0.005 & -0.00014 \\
\hline & $\begin{array}{l}\text { ANFIS-DE/ } \\
\text { SVD }\end{array}$ & 0.115 & $6.5 \mathrm{E}-5$ & 0.0050 & 0.0001 \\
\hline \multirow[t]{3}{*}{2.57} & ANFIS & 0.085 & 0.00074 & 0.0217 & -0.020 \\
\hline & ANFIS-DE & 0.144 & 0.00030 & 0.1410 & -0.00037 \\
\hline & $\begin{array}{l}\text { ANFIS-DE/ } \\
\text { SVD }\end{array}$ & 0.099 & 0.00024 & 0.0123 & -0.0010 \\
\hline \multirow[t]{3}{*}{6.2} & ANFIS & 0.104 & 0.0007 & 0.022 & -0.018 \\
\hline & ANFIS-DE & 0.0944 & 0.00031 & 0.0124 & $-6 E-6$ \\
\hline & $\begin{array}{l}\text { ANFIS-DE/ } \\
\text { SVD }\end{array}$ & 0.088 & 0.00023 & 0.011 & -0.0005 \\
\hline \multirow[t]{3}{*}{ Total } & ANFIS & 0.1226 & 0.0261 & 0.020 & -0.018 \\
\hline & ANFIS-DE & 0.1200 & 0.0156 & 0.0121 & 0.00037 \\
\hline & $\begin{array}{l}\text { ANFIS-DE/ } \\
\text { SVD }\end{array}$ & 0.1113 & 0.0156 & 0.0106 & 0.00026 \\
\hline
\end{tabular}

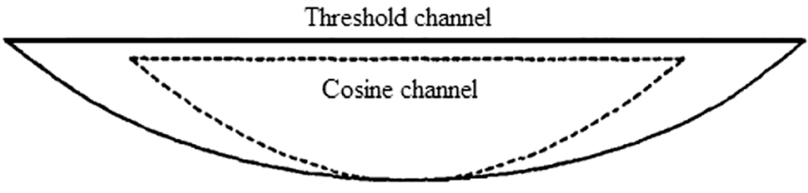

Fig. 10 Comparison of threshold channel and cosine channel profiles (Vigilar and Diplas 1997)

channels as all the predecessors know the general mode for threshold channels like Fig. 10. Accordingly, it has been suggested by researchers that the lateral momentum transfer term induced by turbulence is often applied in their equations which is proposed the shear stress distribution as nonuniform (Cao and Knight 1997; Vigilar and Diplas 1997; Dey 2001). Opposing to classic cosine mode, in the early years by researchers described the theory of stable channels and ignores the lateral diffusion term in their equations with no movement of sediments (Glover and Florey 1951; Parker 1978). In "threshold channel" mode, by increasing flow discharge, the water surface width is increased (widening) and transverse bank slope is gradually decreased associated with sediments movement through the bed and threshold motion of sediments in banks (Yu and Knight 1998). This model is a simple form of natural channel. Therefore, a model that can predict the formed trend of threshold channel well and be far from the original classic mode (cosine channel) is of particular importance. In the highest flow discharge rates (6.2 1/s), ANFIS-DE/SVD model always has the most accuracy than the rest of the models and discharges. Error reduction in ANFIS-DE/SVD model compared to ANFIS-DE and error reduction in ANFIS-DE model compared to ANFIS are evident in all discharges. So that, the hybrid models proposed in this paper can well estimate the physical processes of alluvial channels in which the flow is comfortable (Ackert 2000). Hence, it can be said that using evolutionary algorithm has a significant impact on improvement of performance of classic ANFIS model. And in respond to the mentioned question "Is evolutionary and optimization algorithms in improvement of the performance of ANFIS model is effective or not?" Replied yes these algorithms (especially the optimization algorithm DE) had a positive impact on improving the model performance. As the performance of ANFIS-DE model compared to simple ANFIS about $10.1 \%$, and the ANFIS-DE/SVD compared to ANFIS-DE model almost 7.2\% improved also ANFIS-DE/SVD model accuracy to simple ANFIS model $18.6 \%$ gets better. It can be said that in addition to the use of optimization algorithms DE having a significant impact on increasing the performance of a simple ANFIS model, using evolutionary algorithms ANFIS-DE/SVD causes a reduction in ANFIS-DE model error. It can be seen from the index values for total discharge in Table 3 that the accuracy of the ANFIS-DE/SVD model is more than two ANFIS and ANFIS-DE models. Also, in the graphs of Fig. 8, the equation of the fitted line is drawn for the superior model at each discharge value. The equation of the lines is second-degree polynomial that is in compliance with the results of Vigilar and Diplas (1998) and Dey (2001). Dey (2001) and Khodashenas (2016) considered the polynomial equation as the best and most logical fit for stable channel shape profiles that the lower degree reflects the more accuracy of the model: Diplas and Vigilar (1992) fifth-degree polynomial, then Vigilar and Diplas (1998) third-degree polynomials and in the present study second-degree polynomial as the best fit is suggested. Furthermore, the hybrid ANFIS-DE/SVD models presented in this study as the most accurate model than predecessor models are selected and introduced. Therefore, the hybrid models proposed in this paper can be used to implement and design of stable channels. However, the proposed models are considered and trained based on certain hydraulic conditions according to this paper. Therefore, the application of obtained results in this paper can be applied with some cautions and limitations for other stream geometries, other substrate conditions (cohesive/cohesiveless), other geological conditions in the field and various flow conditions (Hey and Thorne 1986; Gomez 1993; Dade 2000; Davidson and Hey 2011; Kaless et al. 2014; Pfeiffer et al. 2017).

In Fig. 11, the wall of the stable bank for each model in different discharges for better comparison is drawn. It

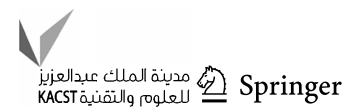


Fig. 11 Stable bank walls at different flow discharges predicted by a experimental model, $\mathbf{b}$ ANFIS, c ANFIS-DE and d ANFIS-DE/SVD models (a)

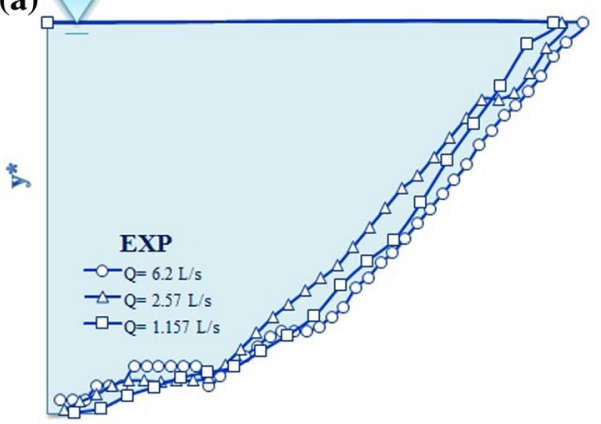

(c)

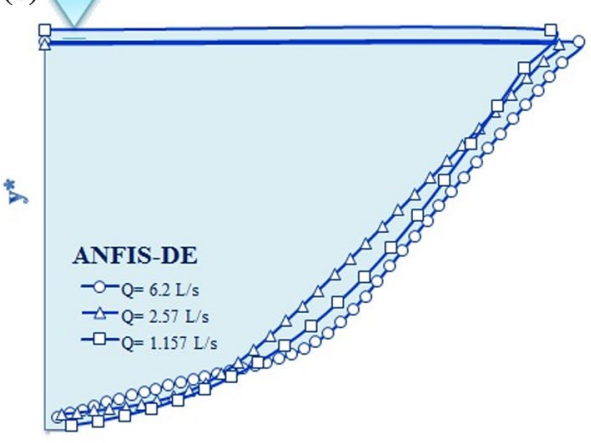

(b)

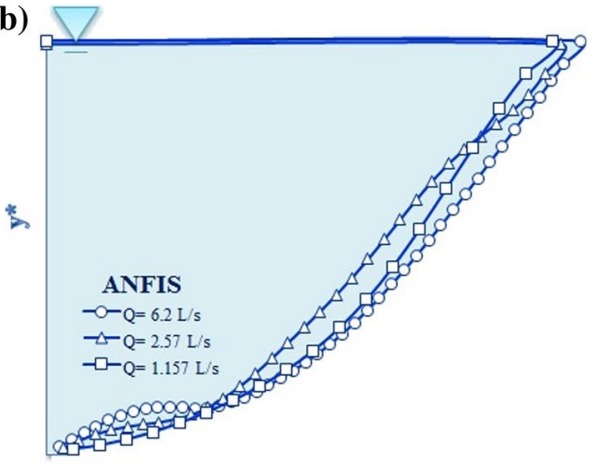

(d)

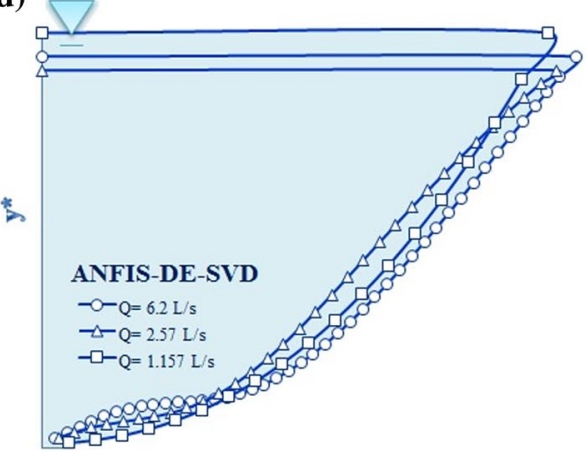

is clear from the figures that in each model by increasing flow discharge, water level widening is well evident that by all models is predicted and have a good conformity with the corresponding experimental values. More conformity of ANFIS model compared to two hybrid models is well observed. But the widening and reduction in the bank slope of the channel to reach stable state cause a reduction in flow depth that at high discharges by two ANFIS-DE and ANFISDE/SVD models which is well simulated. In this mode, the ANFIS-DE model compared to the simple ANFIS model and ANFIS-DE/SVD to ANFIS-DE performing more successful. Notable point at high discharges is clear prediction of this depth reduction by the ANFIS-DE/SVD model that it is known as an advantage of hybrid ANFIS-DE/SVD model.

\section{Conclusions}

Channel dimensions during the stable state formation that no movement of sediment in flow or a mobile bed of particles and threshold banks particles is done have a particular importance. In addition to dimensions, a model that can predict the reasonably shape profile by considering the conditions and governing rules on the threshold channels in design and implementation of stable channel cross section has many applications. In this study, models ANFIS, ANFIS evolved with the use of DE and hybrid ANFIS-DE/ SVD model by defining two objective functions and using of
Pareto curve to predict the shape profile formed in the stable channel banks are designed and evaluated. Furthermore, the main goal of this paper was to extensively examine the performance of different evolutionary algorithms in hybrid with ANFIS model in estimation of the bank profile shapes of stable channels. Review of the results shows that in different flow discharges, all three models are capable of predicting the stable channel profiles accurately and are in good conformity with experimental data. However in general, using evolutionary DE and SVD algorithms causes an improvement in the performance of the classic ANFIS model and the prediction error by these hybrid models is reduced about $20 \%$ in estimation of boundary vertical levels of stable bank profiles. Accordingly, by using DE algorithm and simultaneous DE/SVD algorithm in hybrid with ANFIS model, the ANFIS-DE and ANFIS-DE/SVD models performance improves about $10 \%$ and $18.6 \%$ compared to classic ANFIS model. Moreover, also using DE/SVD causes to increase the efficiency of ANFIS-DE/SVD model equal to $7.2 \%$ compared to ANFIS-DE model. Therefore, it can be pointed out to high ability of hybrid models in estimation of bank profile shapes and can be used as alternative to classic ANFIS model in design and implementation of stable channels. In high discharges, the hybrid ANFIS-DE/SVD model is capable well of predicting the water surface widening, reducing the slope and depth of the channel which are the advantages of this model compared to the classic ANFIS model. However, it should be attention and cautions to limitation of 
these models in estimation of cross-sectional bank profile shapes of stable channel in other hydraulic, geometry and geomorphologic conditions different with available observed conditions in this paper. Following the research, other clustering and sampling algorithms [fuzzy $C$-means clustering (ANFIS-FCM) and ANFIS-SC] in prediction of dimensions and shape of stable channels are recommended.

Open Access This article is distributed under the terms of the Creative Commons Attribution 4.0 International License (http://creativeco mmons.org/licenses/by/4.0/), which permits unrestricted use, distribution, and reproduction in any medium, provided you give appropriate credit to the original author(s) and the source, provide a link to the Creative Commons license, and indicate if changes were made.

\section{References}

Ackert SF (2000) A study of different methods for determination of regime channel geometry with application to streams in southwestern Ontario. Ph.D. thesis, University of Windsor

Afzalimehr H, Abdolhosseini M, Singh VP (2010) Hydraulic geometry relations for stable channel design. J Hydrol Eng 15(10):859-864

Ahmadianfar I, Adib A, Taghian M (2017) Optimization of multi-reservoir operation with a new hedging rule: application of fuzzy set theory and NSGA-II. Appl Water Sci 7(6):3075-3086

Azimi H, Bonakdari H, Ebtehaj I, Ashraf Talesh SH, Jamali A (2016) Evolutionary Pareto optimization of an ANFIS network for modeling scour at pile groups in clear water condition. Fuzzy Sets Syst 319:50-69

Babaeyan-Koopaei K, Valentine EM (1998) Bank profiles of selfformed straight stable channels. In: Proceedings of the third international conference on hydroscience and engineering, Cottbus/ Berlin, Germany, 31 Aug/3 Sept

Bonakdari H, Gholami A (2016) Evaluation of artificial neural network model and statistical analysis relationships to predict the stable channel width. In: River Flow 2016, Iowa City, USA, 11-14 July

Bonakdari H, Zaji AH (2018) New type side weir discharge coefficient simulation using three novel hybrid adaptive neuro-fuzzy inference systems. Appl Water Sci 8(1):10

Cao S, Knight DW (1997) Entropy-based design approach of threshold alluvial channels. J Hydraul Res 35(4):505-524

Dade WB (2000) Grain size, sediment transport and alluvial channel pattern. Geomorphology 35(1-2):119-126

Dariane AB, Azimi S (2016) Forecasting streamflow by combination of a genetic input selection algorithm and wavelet transforms using ANFIS models. Hydrol Sci J 61(3):585-600

Davidson SK, Hey RD (2011) Regime equations for natural meandering cobble-and gravel-bed rivers. J Hydraul Eng 137(9):894-910

Dey S (2001) Bank profile of threshold channels: a simplified approach. J Irrig Drain Eng ASCE 127(3):184-187

Diop L, Bodian A, Djaman K, Yaseen ZM, Deo RC, El-Shafie A, Brown LC (2018) The influence of climatic inputs on stream-flow pattern forecasting: case study of Upper Senegal River. Environ Earth Sci 77(5):182

Diplas P (1990) Characteristics of self-formed straight channels. J Hydraul Eng ASCE 116(5):707-728

Diplas P, Vigilar G (1992) Hydraulic geometry of threshold channels. J Hydraul Eng ASCE 118(4):597-614

Ebtehaj I, Bonakdari H, Shamshirband S (2016) Extreme learning machine assessment for estimating sediment transport in open channels. Eng Comput 32(4):691-704
Ebtehaj I, Bonakdari H, Moradi F, Gharabaghi B, Khozani ZS (2018) An integrated framework of extreme learning machines for predicting scour at pile groups in clear water condition. Coast Eng 135:1-15

Ebtehaj I, Bonakdari H, Gharabaghi B (2019) A reliable linear method for modeling lake level fluctuations. J Hydrol 570:236-250

Gandomi AH, Roke DA (2013) Intelligent formulation of structural engineering systems. In: Seventh M.I.T. conference on computational fluid and solid mechanics-focus: multiphysics \& multiscale, Massachusetts Institute of Technology, Cambridge, MA, 12 June

Gholami A, Bonakdari H, Zaji AH, Ajeel Fenjan S, Akhtari AA (2016a) Design of modified structure multi-layer perceptron networks based on decision trees for the prediction of flow parameters in $90^{\circ}$ open-channel bends. Eng Appl Comput Fluid Mech 10(1):193-208

Gholami A, Bonakdari H, Zaji AH, Michelson DG, Akhtari AA (2016b) Improving the performance of multi-layer perceptron and radial basis function models with a decision tree model to predict flow variables in a sharp 90 bend. Appl Soft Comput 48:563-583

Gholami A, Bonakdari H, Ebtehaj I, Shaghaghi S, Khoshbin F (2017a) Developing an expert group method of data handling system for predicting the geometry of a stable channel with a gravel bed. Earth Surf Proc Land 42(10):1460-1471

Gholami A, Bonakdari H, Ebtehaj I, Akhtari AA (2017b) Design of an adaptive neuro-fuzzy computing technique for predicting flow variables in a $90^{\circ}$ sharp bend. J Hydroinform 19(4):572-585

Gholami A, Bonakdari H, Zaji AH, Fenjan SA, Akhtari AA (2017c) New radial basis function network method based on decision trees to predict flow variables in a curved channel. Neural Comput Appl 30:2771-2785

Gholami A, Bonakdari H, Akhtari AA, Ebtehaj I (2017d) A combination of computational fluid dynamics, artificial neural network and support vectors machines model to predict flow variables in curved channel. Sci Iran. https://doi.org/10.24200/sci.2017.4520

Gholami A, Bonakdari H, Ebtehaj I, Gharabaghi B, Khodashenas SR, Talesh SHA, Jamali A (2018a) A methodological approach of predicting threshold channel bank profile by multi-objective evolutionary optimization of ANFIS. Eng Geol 239:298-309

Gholami A, Bonakdari H, Zeynoddin M, Ebtehaj I, Gharabaghi B, Khodashenas SR (2018b) Reliable method of determining stable threshold channel shape using experimental and gene expression programming techniques. Neural Comput Appl. https://doi. org/10.1007/s00521-018-3411-7

Gholami A, Bonakdari H, Ebtehaj I, Mohammadian M, Gharabaghi B, Khodashenas SR (2018c) Uncertainty analysis of intelligent model of hybrid genetic algorithm and particle swarm optimization with ANFIS to predict threshold bank profile shape based on digital laser approach sensing. Measurement 121:294-303

Gholami A, Bonakdari H, Zaji AH, Akhtari AA (2019) A comparison of artificial intelligence-based classification techniques in predicting flow variables in sharp curved channels. Eng Comput. https:// doi.org/10.1007/s00366-018-00697-7

Ghorbani MA, Khatibi R, Karimi V, Yaseen ZM, Zounemat-Kermani M (2018) Learning from multiple models using artificial intelligence to improve model prediction accuracies: application to river flows. Water Resour Manage 32(13):4201-4215

Glover RE, Florey QL (1951) Stable channel profiles. Hydraulic Laboratory Report 325, U.S. Bureau of Reclamation, Washington

Golub GH, Reinsch C (1970) Singular value decomposition and least squares solutions. Numer Math 14(5):403-420

Gomez B (1993) Roughness of stable, armored gravel beds. Water Resour Res 29(11):3631-3642

Hey RD, Thorne CR (1986) Stable channels with mobile gravel beds. J Hydraul Eng 112(8):671-689

Hosseini K, Nodoushan EJ, Barati R, Shahheydari H (2016) Optimal design of labyrinth spillways using meta-heuristic algorithms. KSCE J Civ Eng 20(1):468-477

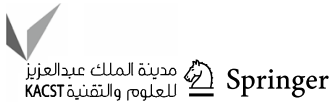


Ikeda S (1981) Self-formed straight channels in sandy beds. J Hydraul Div ASCE 107:389-406

Ikeda S, Parker G, Kimura Y (1988) Stable width and depth of straight gravel rivers with heterogeneous bed materials. Water Resour Res 24:713-722

Joshi I, Dai W, Bilal A, Upreti AR, He Z (2018) Evaluation and comparison of extremal hypothesis-based regime methods. Water 10(3):271

Kaless G, Mao L, Lenzi MA (2014) Regime theories in gravel-bed rivers: models, controlling variables, and applications in disturbed Italian rivers. Hydrol Process 28(4):2348-2360

Karaboga D, Kaya E (2018) Adaptive network based fuzzy inference system (ANFIS) training approaches: a comprehensive survey. Artif Intell Rev. https://doi.org/10.1007/s10462-017-9610-2

Karkevandi-Talkhooncheh A, Hajirezaie S, Hemmati-Sarapardeh A, Husein MM, Karan K, Sharifi M (2017) Application of adaptive neuro fuzzy interface system optimized with evolutionary algorithms for modeling $\mathrm{CO}_{2}$-crude oil minimum miscibility pressure. Fuel 205:34-45

Khalkhali A, Mostafapour M, Tabatabaie SM, Ansari B (2016) Multiobjective crashworthiness optimization of perforated square tubes using modified NSGAII and MOPSO. Struct Multidiscip Optim 54:45-61

Khodashenas SR (2016) Threshold gravel channels bank profile: a comparison among 13 models. Int J River Basin Manag 14:337-344

Khoshbin F, Bonakdari H, Ashraf Talesh SH, Ebtehaj I, Zaji AH, Azimi H (2016) Adaptive neuro-fuzzy inference system multiobjective optimization using the genetic algorithm/singular value decomposition method for modelling the discharge coefficient in rectangular sharp-crested side weirs. Eng Opt 48(6):933-948

Khosravi K, Mao L, Kisi O, Yaseen ZM, Shahid S (2018) Quantifying hourly suspended sediment load using data mining models: case study of a glacierized Andean catchment in Chile. J Hydrol 567:165-179

Kisi O, Yaseen ZM (2019) The potential of hybrid evolutionary fuzzy intelligence model for suspended sediment concentration prediction. CATENA 174:11-23

Lee JS, Julien PY (2006) Downstream hydraulic geometry of alluvial channels. J Hydraul Eng 132(12):1347-1352

Li J, Salim RD, Aldlemy MS, Abdullah JM, Yaseen ZM (2018) Fiberglass-reinforced polyester composites fatigue prediction using novel data-intelligence model. Arab J Sci Eng. https://doi. org/10.1007/s13369-018-3508-4

Madvar HR, Ayyoubzadeh SA, Atani MGH (2011) Developing an expert system for predicting alluvial channel geometry using ANN. Expert Syst Appl 38(1):215-222

Manu DS, Thalla AK (2017) Artificial intelligence models for predicting the performance of biological wastewater treatment plant in the removal of Kjeldahl nitrogen from wastewater. Appl Water Sci 7(7):3783-3791

Métivier F, Devauchelle O, Chauvet H, Lajeunesse E, Meunier P, Ashmore $P$ et al (2016) Geometry of meandering and braided gravelbed threads from the Bayanbulak Grassland, Tianshan, PR China. Earth Surf Dyn 4(1):273-283

Mikhailova NA, Shevchenko OB, Selyametov MM (1980) Laboratory of investigation of the formation of stable channels. Hydrotech Constr 14:714-722

Nouiri I (2017) Optimal design and management of chlorination in drinking water networks: a multi-objective approach using genetic algorithms and the Pareto optimality concept. Appl Water Sci 7(7):3527-3538

Parker G (1978) Self-formed straight rivers with equilibrium banks and mobile bed, Part 2. The gravel river. J Fluid Mech 89(01):127-146

Pfeiffer AM, Finnegan NJ, Willenbring JK (2017) Sediment supply controls equilibrium channel geometry in gravel rivers. Proc Natl Acad Sci 114(13):3346-3351

Pizzuto JE (1990) Numerical simulation of gravel river widening. Water Resour Res 26:1971-1980
Saba T, Rehman A, AlGhamdi JS (2017) Weather forecasting based on hybrid neural model. Appl Water Sci 7(7):3869-3874

Sanikhani H, Deo RC, Samui P, Kisi O, Mert C, Mirabbasi R et al (2018) Survey of different data-intelligent modeling strategies for forecasting air temperature using geographic information as model predictors. Comput Electron Agric 152:242-260

Shaghaghi S, Bonakdari H, Gholami A, Ebtehaj I, Zeinolabedini M (2017) Comparative analysis of GMDH neural network based on genetic algorithm and particle swarm optimization in stable channel design. Appl Math Comput 313:271-286

Shaghaghi S, Bonakdari H, Gholami A, Kisi O, Shiri J, Binns AD, Gharabaghi B (2018a) Stable alluvial channel design using evolutionary neural networks. J Hydrol 566:770-782

Shaghaghi S, Bonakdari H, Gholami A, Kisi O, Binns A, Gharabaghi B (2018b) Predicting the geometry of regime rivers using M5 model tree, multivariate adaptive regression splines and least square support vector regression methods. Int J River Basin Manag. https:// doi.org/10.1080/15715124.2018.1546731

Singh T, Pal M, Arora VK (2017) Modeling of oblique load test on batter pile group based on support vector machines and Gaussian regression. Geotech Geol Eng 36:1597-1607

Stebbings J (1963) The shapes of self-formed model alluvial channels. Proc Inst Civ Eng 25(4):485-510

Storn R, Price K (1997) Differential evolution-a simple and efficient heuristic for global optimization over continuous spaces. J Glob Optim 11:341-359

Sulaiman SO, Shiri J, Shiralizadeh H, Kisi O, Yaseen ZM (2018) Precipitation pattern modeling using cross-station perception: regional investigation. Environ Earth Sci 77(19):709

Taher-Shamsi A, Tabatabai MRM, Shirkhani R (2013) An evaluation model of artificial neural network to predict stable width in gravel bed rivers. Int J Environ Sci Technol 9:333-342

Takagi T, Sugeno M (1985) Fuzzy identification of systems and its applications to modeling and control. IEEE Trans Syst Man Cybern 1:116-132

Tao H, Diop L, Bodian A, Djaman K, Ndiaye PM, Yaseen ZM (2018a) Reference evapotranspiration prediction using hybridized fuzzy model with firefly algorithm: regional case study in Burkina Faso. Agric Water Manag 208:140-151

Tao H, Sulaiman SO, Yaseen ZM, Asadi H, Meshram SG, Ghorbani MA (2018b) What is the potential of integrating phase space reconstruction with SVM-FFA data-intelligence model? Application of rainfall forecasting over regional scale. Water Resour Manag 32(12):3935-3959

Vigilar G, Diplas P (1997) Stable channels with mobile bed: formulation and numerical solution. J Hydraul Eng ASCE 123(3):189-199

Vigilar G, Diplas P (1998) Stable channels with mobile bed: model verification and graphical solution. J Hydraul Eng ASCE 124(11):1097-1108

Yalin MS (1992) River mechanics. Elsevier, New York, p 219

Yaseen ZM, Ehteram M, Sharafati A, Shahid S, Al-Ansari N, El-Shafie A (2018a) The integration of nature-inspired algorithms with least square support vector regression models: application to modeling river dissolved oxygen concentration. Water 10(9):1124

Yaseen ZM, Tran MT, Kim S, Bakhshpoori T, Deo RC (2018b) Shear strength prediction of steel fiber reinforced concrete beam using hybrid intelligence models: a new approach. Eng Struct 177:244-255

Yu G, Knight DW (1998) Geometry of self-formed straight threshold channels in uniform material. Proc Inst Civ Eng Water Marit Energy Lond 130(1):31-41

Publisher's Note Springer Nature remains neutral with regard to jurisdictional claims in published maps and institutional affiliations. 